\section{Periosteal reactions in African children}

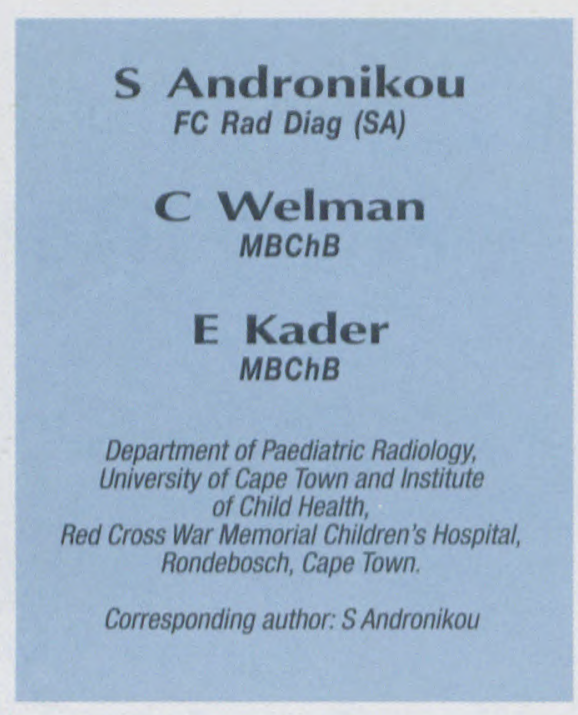

involvement, whether the periosteal reactions are unifocal or multifocal, and if multifocal, whether they are bilaterally symmetrical or asymmetrical. These features must be considered in conjunction with the patient's age and clinical history. This pictorial review demonstrates a range of these conditions and concentrates on those encountered in the African setting while highlighting their differentiating features.

\section{Introduction}

There is a wide differential for periosteal reactions in the paediatric age group. In addition to the common causes of periosteal reactions seen in first world communities, African children present with dramatic radiological images of various nutritional and infective diseases that are endemic in third world communities. This pictorial review demonstrates a variety of these periosteal reactions and lists features to allow differentiation based on the conventional radiography, the age of the child and the clinical history.

\section{Discussion}

A periosteal reaction seen on conventional radiographs is the new bone formation occurring in response to a stimulus. It may either be due to a generalised metabolic condition or from local elevation of the periosteum 



\section{Periosteal reactions in African children}

\section{from page 4}

by trauma, infection or neoplastic cells. Since it is a non-specific reaction to various causes, the differential diagnosis is potentially large. Diagnosis is aided by grouping periosteal reactions according to various conventional radiograph features. These features include site of involvement and whether the periosteal reactions are bilaterally symmetrical, asymmetrical or focal. (Tables 1-3). The patient age and clinical history is also useful in narrowing the differential diagnosis down. ${ }^{1}$ There are also associated local and distant conventional radiograph features that allow for aetiological differentiation.

\section{Table 1 : Causes for bilaterally symmetrical periosteal reactions}

\section{Bilaterally Symmetrical}
1. Normal infant
2. Congenital syphilis
3. Rickets
4. Scurvy
5. Acute leukaemia
6. Hypertrophic oesteoarthropathy
7. Juvenile chronic arthritis
8. Caffey's disease
9. Prostaglandin $\mathrm{E}_{\text {, therapy }}$

\section{Table 2 : Causes for bilaterally asymmetrical periosteal reactions}

\section{Bilaterally Asymmetrical}

1. Multifocal osteomyelitis

2. Non-accidental injury

3. Metastases (neuroblastoma)

4. Tuberculosis

5. Sickle-cell dactylitis (hand-foot syndrome)

6. Bleeding diatheses (haemophilia)

\section{Table 3 : Causes for focal periosteal reactions}

\section{Focal}

1. Trauma (including stress fractures)

2. Osteomyelitis

3. Neoplasm (Ewing's sarcoma, osteosarcoma, eosinophilic granuloma, osteoid osteoma)

Bilaterally symmetrical periosteal reactions: Table 1 lists the causes for bilaterally symmetrical periosteal reactions. A single lamellar diaphyseal periosteal reaction may occasionally be seen in normal infants with no pathological cause attributable. ${ }^{1}$ In congenital syphilis (Figures 1 and 2), the metaphyseal lucent band is the commonest reported finding. The epiphysis is generally spared. Up to $95 \%$ of infants with congenital syphilis have bone changes. These are often not seen at birth but increase in inci-

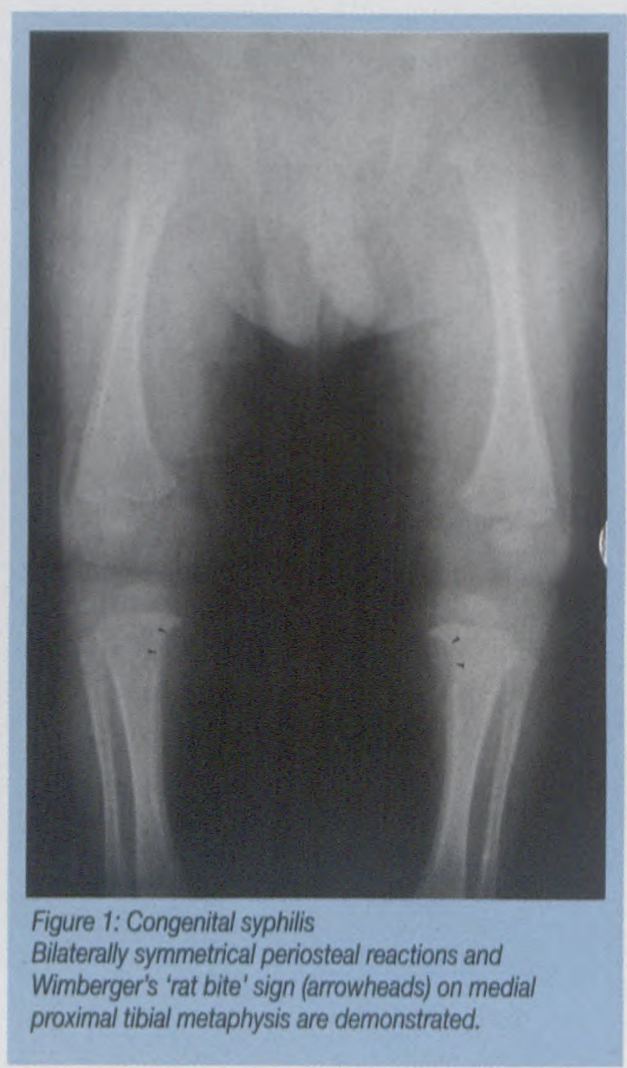

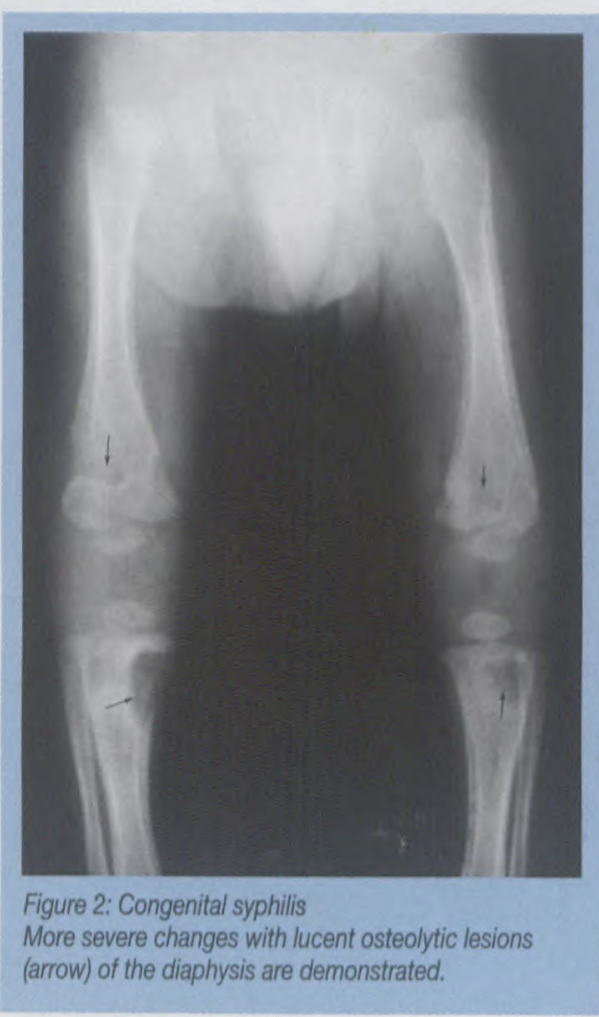

dence after the neonatal period. The bone changes usually resolve by nine months of age. ${ }^{1-3}$

Rickets (Figures 3 and 4 ) in southern Africa is most commonly due to vitamin $\mathrm{D}$ deficiency and is usually only seen beyond four months of age when maternally derived stores have been depleted. It affects multiple sites (including skull and chest) but is most evident at sites of rapid bone growth i.e. wrists and knees. ${ }^{1,4}$ Scurvy (Figures 7 and 8) rarely occurs prior to four months of age due to maternally derived stores of vitamin $C$, but may present after this period with limb pain mimicking osteitis or arthritis in infants fed with unsupplemented cows milk. ${ }^{1,5,6}$

Acute Leukaemia (Figure 9) is associated with osteopaenia and prominent metaphyseal bone resorption with or without a dense zone of provisional calcification. ${ }^{1,7}$ Hypertrophic osteoarthropathy (Figure 10) in children occurs most commonly with 


\section{Periosteal reactions in African children}

\section{from page 6}
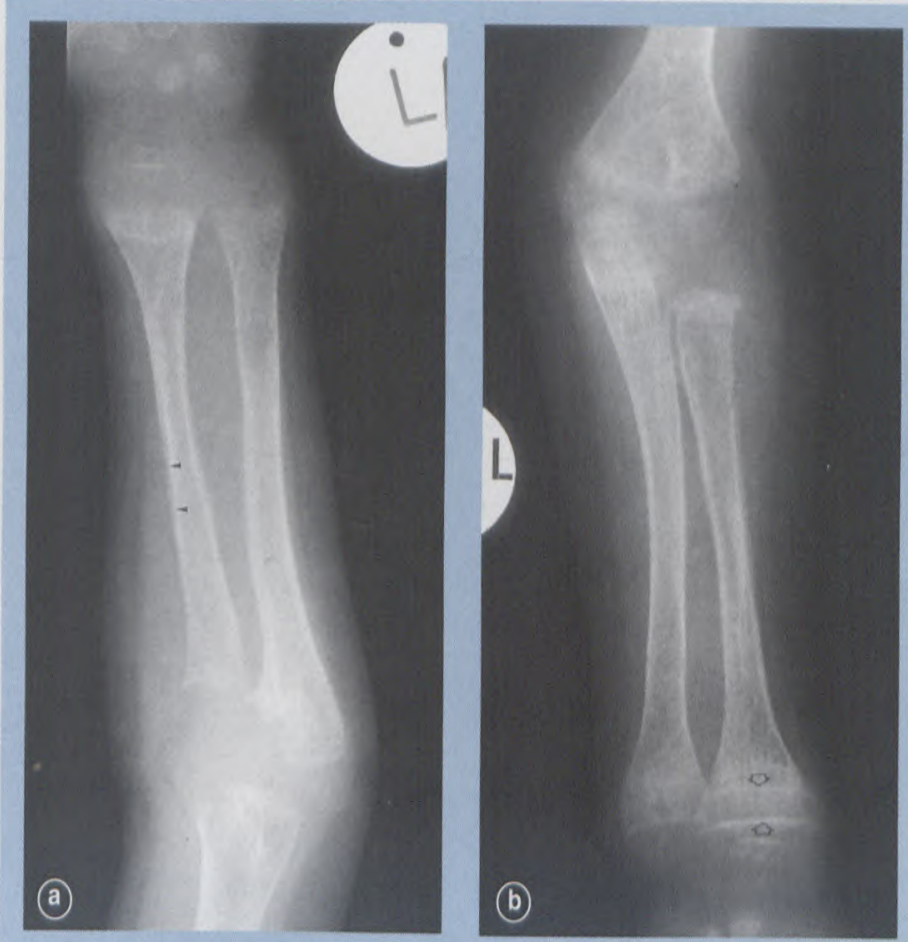

Figure 3 : Rickets

Before treatment this patient demonstrates ill-defined/absent epiphysis, a splayed, cupped and frayed metaphysis; a widened growth plate due to uncalcified osteoid; osteopaenia and a bilaterally symmetrical apparent periosteal reaction (arrowheads) due to uncalcified subperiosteal osteoid. After treatment there is better definition of the metaphyseal ends due to calcification of the previously uncalcified osteoid (open arrows).
(Figure 14) are commonly in the periarticular regions of the phal anges, metacarpals and metatarsals. ${ }^{1}$ Caffey's disease (Figure 15) occurs before 5 months of age. It typically involves the mandible, clavicles and ribs. Asymmetric involvement of ribs and long bones may occur. ${ }^{8}$ Prostaglandin $E_{1}$ therapy for patent ductus arteriosus may lead to periosteal reacbronchiectasis following measles or pulmonary tuberculosis. Periosteal reactions in juvenile chronic arthritis

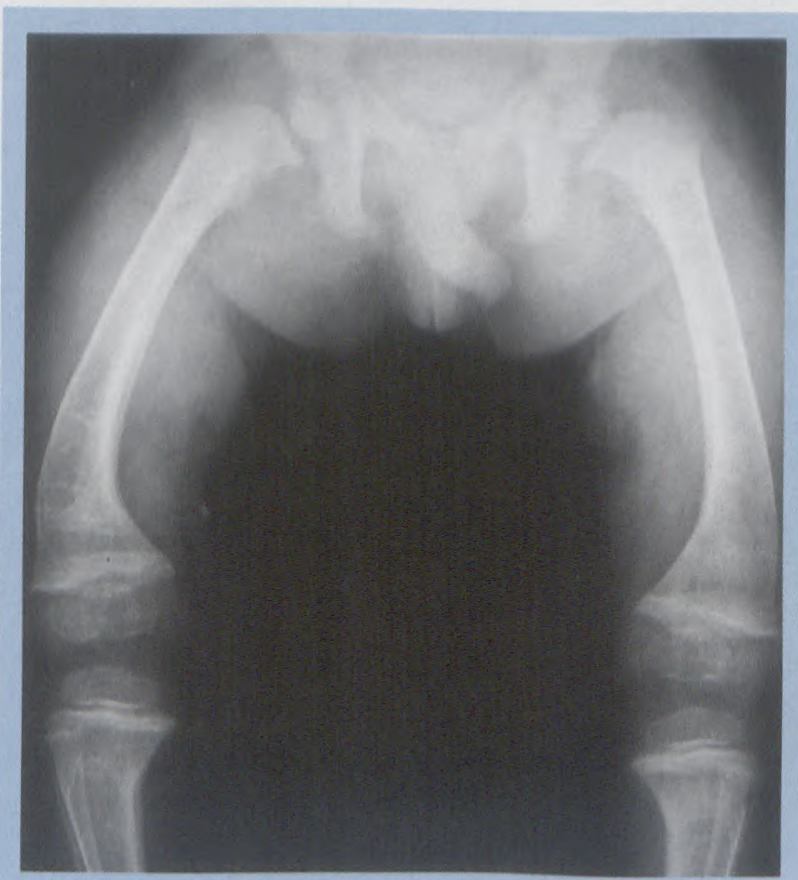

Figure 4 : Rickets

Long-term sequelae with bowing deformities and attempted remodelling of the long bones are seen. tions after more than a month of therapy. It is very seldom seen as surgical repair is usually undertaken before the bone changes occur. ${ }^{1,9}$

\section{Bilaterally asym-} metrical periosteal reactions: Table 2 lists the causes for a bilaterally asymmetrical periosteal reactions. Non-accidental injury (Figure 11) typically manifests as multiple fractures in varying stages of healing which are not accounted for by a plausible history or by underlying causes such as a bone dysplasia or a metabolic disorder. Besides corner and bucket handle fractures
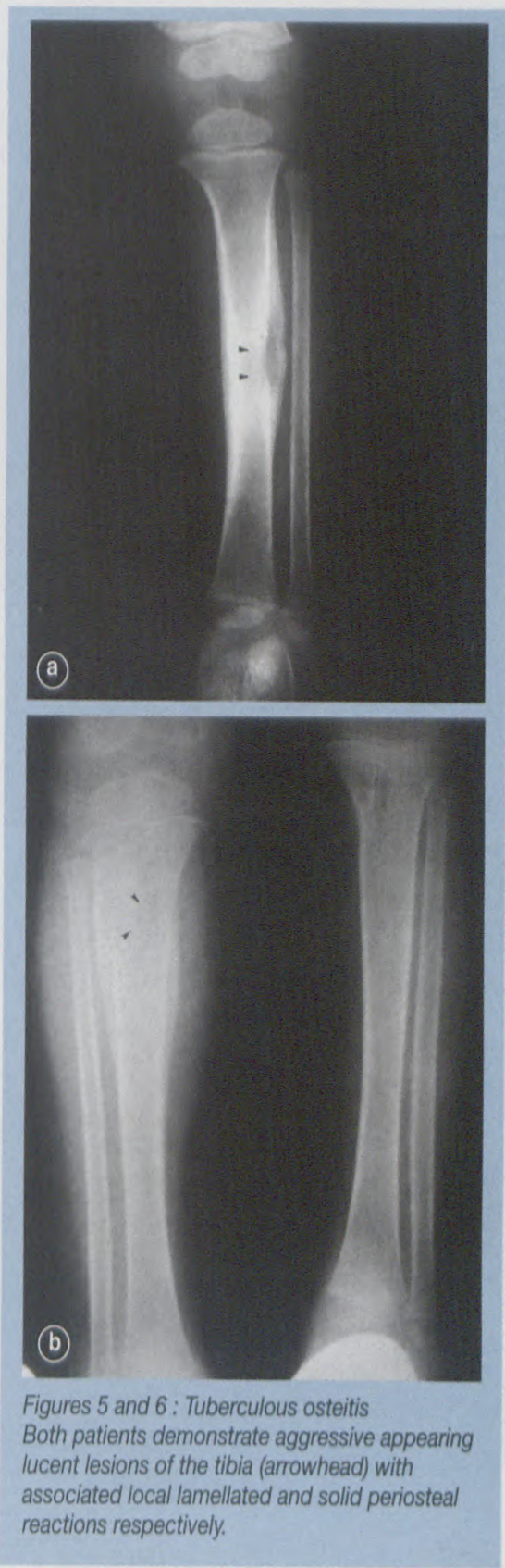

through the metaphyses, fractures involving the posterior ribs, scapulae, spine and small bones of the hand and feet are highly specific for NAI. Skull fractures with or without intracranial injuries and visceral injuries are also frequently seen. ${ }^{1}$ Tuberculous osteitis (Figures 5 and 6 ) in young children may involve multiple sites including the diaphyses of long bones and the small bones of the hands and feet. The features of cortical breakthrough, 


\section{Periosteal reactions in African children}

\section{from page 7}

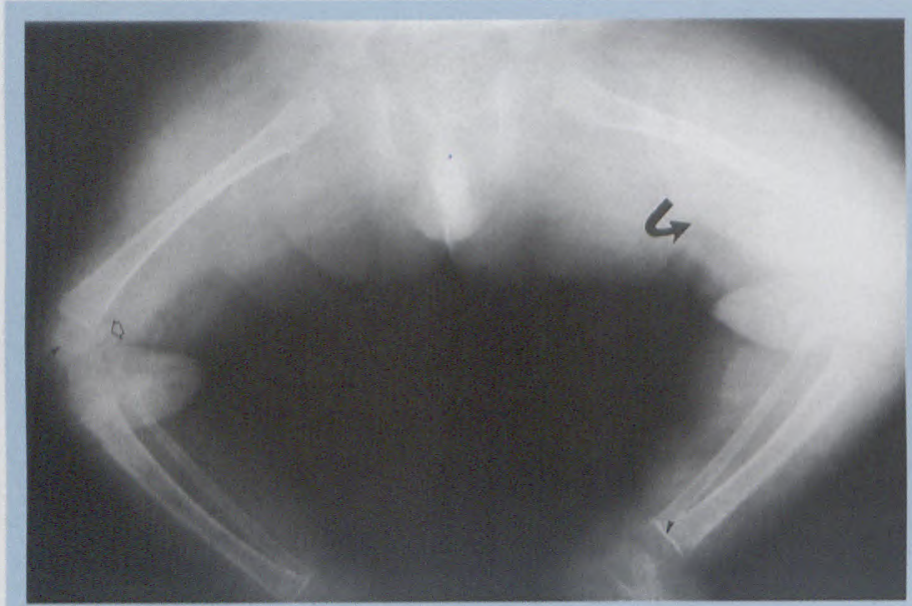

Figures 7 and 8 : Scurvy

The pre-treatment image demonstrates generalised osteopaenia, the characteristic Wimberger's ring (pencil this epiphyseal cortex) (small arrow), Frankel's line (dense zone of provisional calcification) (arrowhead) and Pelkan spurs (metaphyseal corner

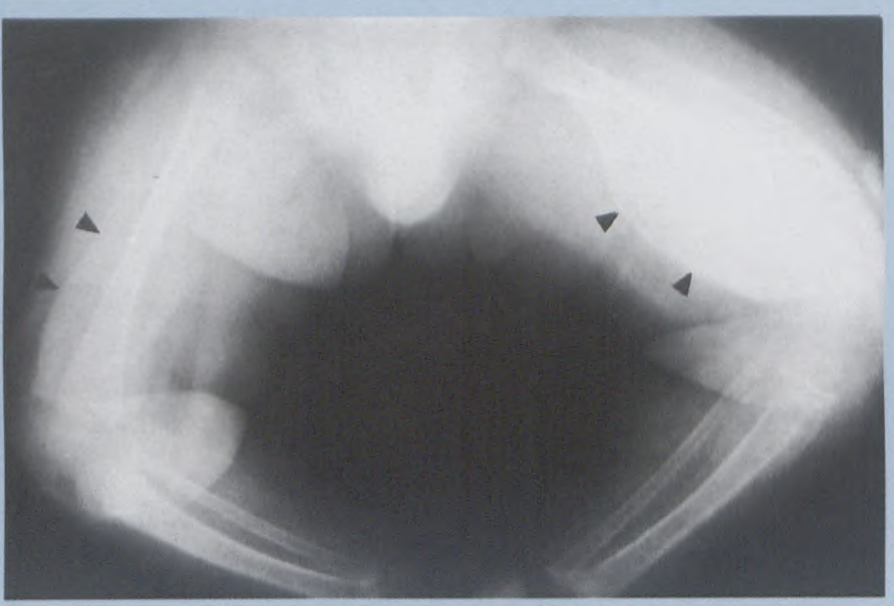

fractures) (open arrow). The soft tissue mass surrounding the diaphysis represents a subperiostal haematoma (curved arrow). After treatment the periosteum and haematoma calcify showing its bilaterally symmetrical nature (big arrowheads). poor zone of transition and lamellated periosteal reaction are indistinguishable from a malignant neoplasm and without a suggestive chest radiograph or positive skin test, biopsy may be the only means of differentiation. Tuberculous bone infection in older children

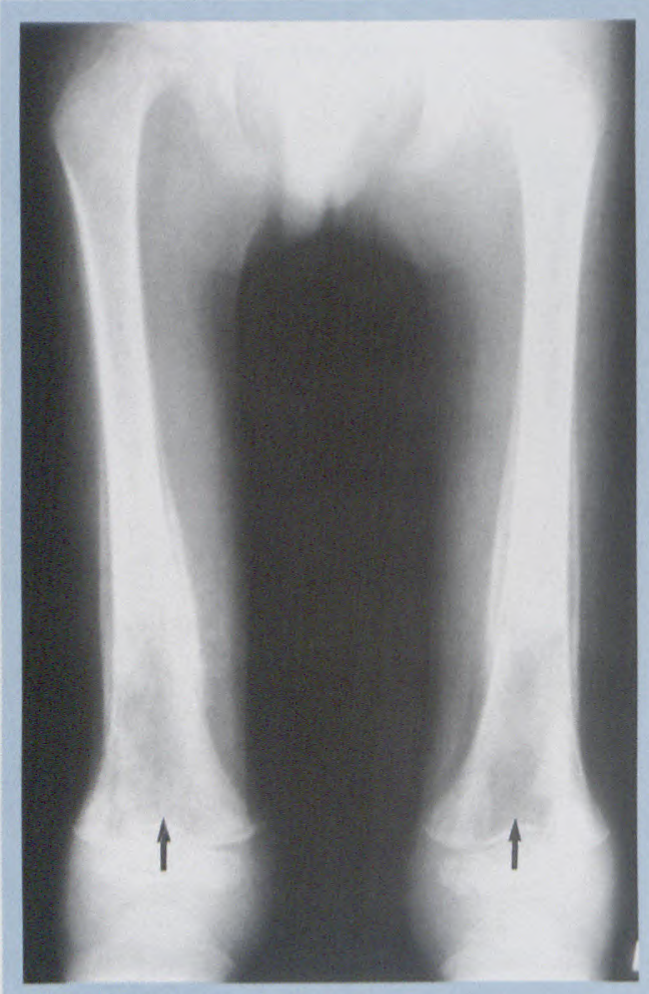

Figure 9: Leukaemia

The lucent metaphyseal bands (arrows) are characteristic of leukaemic infiltration as are the accompanying periosteal reactions.
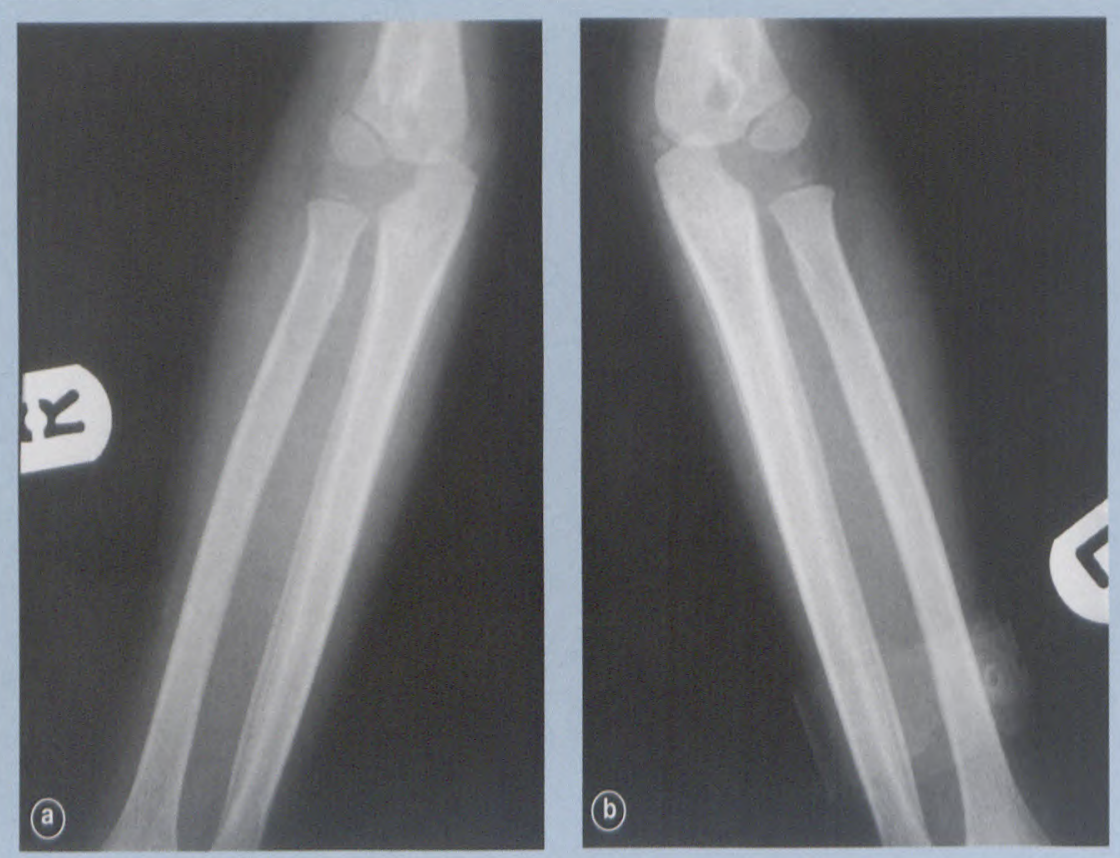

Figure 10: Hypertrophic osteoarthropathy

Lamellated periosteal reactions are demonstrated in a child with bronchiectasis.

more commonly affects the spine and joints. ${ }^{10,11}$ Sickle-cell dactylitis (hand-foot syndrome) occurs in children aged six months to two years of age (Figure 13). Soft tissue swelling with patchy lucency and sclerosis of the metacarpal, metatarsal and phalangeal shafts can be seen. Marrow hyperplasia leads to widening of the skull diploic space. Sickling leads to vascular infarcts - square-shaped compression infarcts of the vertebral endplates are diagnostic. Bleeding diatheses have other features involving the joints and bones which aid in this diagnosis. Metastases (Figure 12) may produce periosteal reactions with or without associated bone lesions. ${ }^{1}$ 


\section{Periosteal reactions in African children}

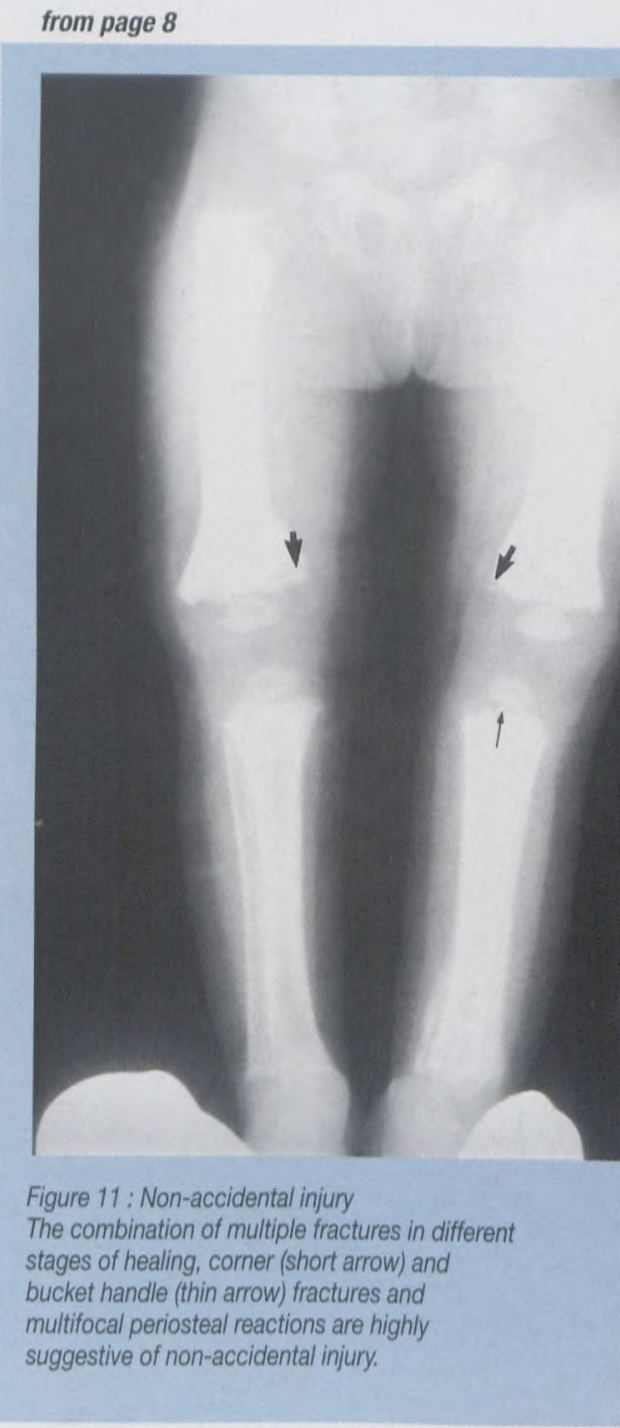

Focal periosteal reactions: Table 3 lists the causes for a focal periosteal reaction. In these cases the cause is often an obvious history as in subacute (Figure 16 ) $^{12}$ or acute trauma or on assessment of the radiograph as in primary bone neoplasms (Figure 18). ${ }^{13}$ The bone changes of osteomyelitis (Figure 17) occur late in the disease and the diagnosis is preferably made on technetium bone scan and biopsy. ${ }^{14}$

\section{Conclusion}

Important differentiating features of periosteal reactions include:

- Age of child

- Associated clinical history

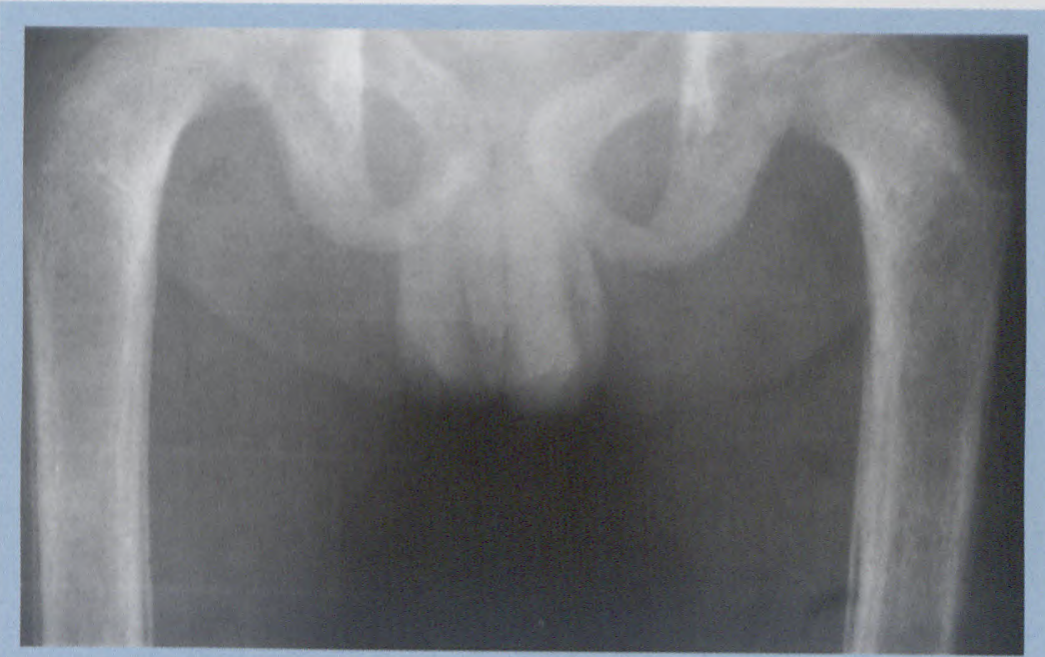

Figure 12 : Neuroblastoma metastases

These may cause periosteal reactions with or without lytic bone lesions.

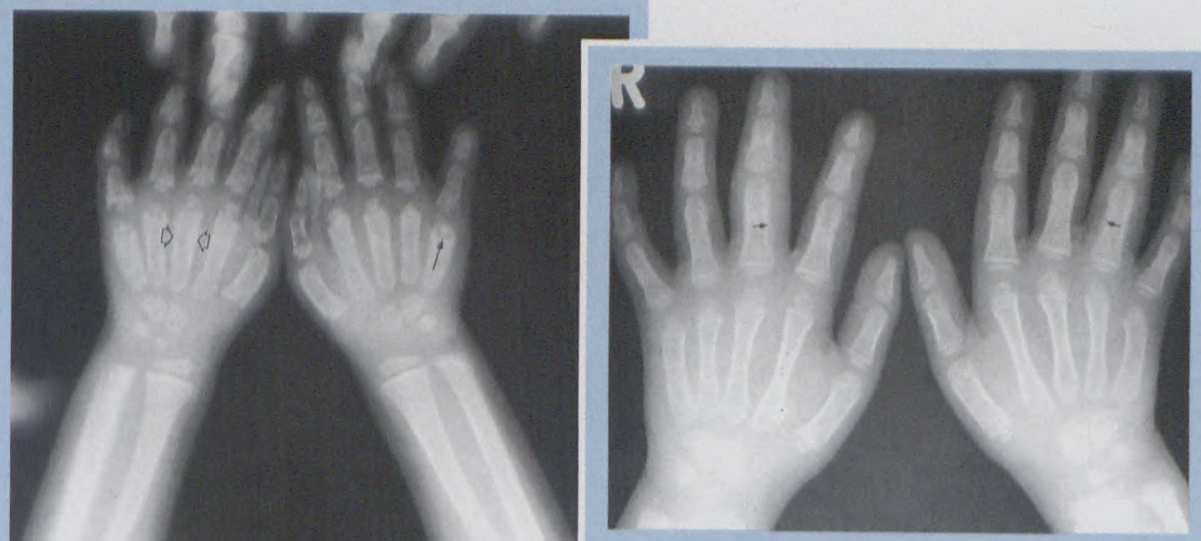

Figure 14 : Juvenile chronic arthritis

Soft tissue swelling and a periosteal reaction are present over the proximal phalanges of right middle and left ring fingers (arrows). There is associated generalized osteopaenia but no periarticular erosions.

\section{References}

1. Chapman S, Nakielny R. Aids to radiological differential diagrosis. $3^{\text {std }}$ ed. London:WB Saunders. 1995;34-43.569-571,596,602603

Figure 13 : Sickle-cell anaemia

Typical changes of sickle cell disease are present in the hands with 'egg-in-cup' epiphysis in metaphyses (thin arrow), widened medullary cavities (open arrows), coarse trabecular and an associated periosteal reaction in the right radius and ulna (arrowheads).

- Whether unifocal or multifocal - If multifocal, whether bilaterally symmetrical or asymmetrical

- Anatomical and geographic location of periosteal reaction

- Associated specific bone changes
2. Hira SK, Bhat GJ, Patel JB, et al.Early congenital syphilis c dinicoradiological features in 202 patients. Sex Transm Dis 1985; 12 : 177-183

3. Cremin BJ, Fisher RM. The lesions of congenital syphilis. Br. J Radiol 1970; 43:333-341

4. Pettifor JM. Metabolic bone disorders. In: Coovadia HM Loening WEK (eds). Paediatrics and child health: A handbook for health professionals in the third world, $3^{\text {id }}$ ed. Cape Town: Oxford University Press. 1992; 455-459

5. Ramar S, Sivaramakrishnan V, Manoharan K. Scurvy-a forgotten disease, Arch Phys Med Rehabil 1993; 74:92-95

6. Hansen J. Nutritional disorders. In: Coovadia HM, Loening WEK (eds). Paediatrics and child health: A handbook for health professionals in the third world, $3^{\text {nd }}$ ed. Cape Town: Oxford University Press. 1992; 152-153

7. Nixon GW, Gwinn JL. The roentgen manifestations of leukaemia in infancy. Radiologyl973; 107:603-609

8. Padfield E, Hicken P. Cortiical hyperostosis in infants: a radiological study of sixteen patients. BrJ Radiol 1970;43:231- 


\section{Periosteal reactions in African children}

\section{from page 9}
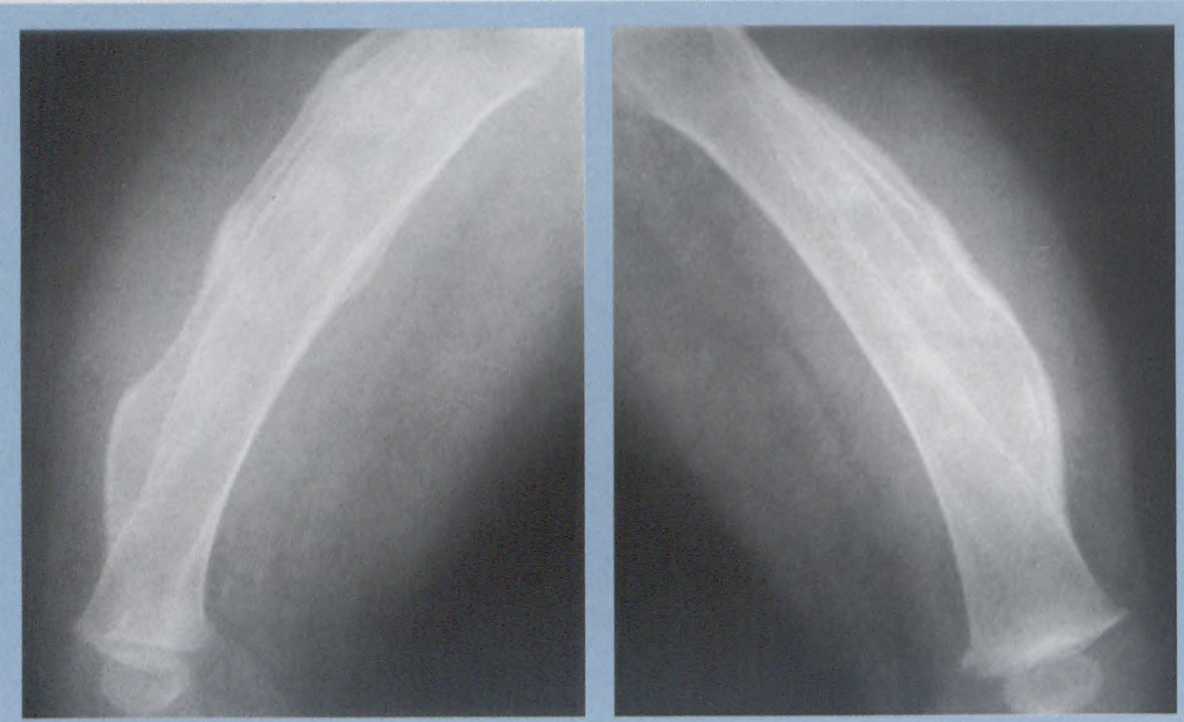

Figure 15: Caffey's Disease

A florid diaphyseal periosteal reaction with bony bowing deformities, expansion and remodelling of both femurs is seen in a child with Caffey's Disease.

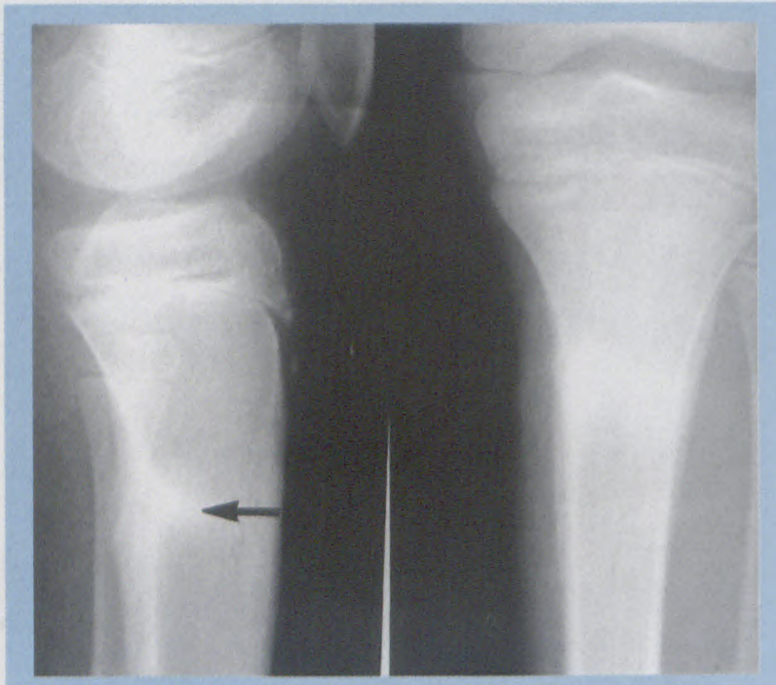

Figure 16 : Trauma

The transverse sclerotic band (arrow) in the proximal tibia represents a healing stress fracture with an associated periosteal reaction.
9. Faye-Petersen OM, Johnson Jr WH, Carlo WA, Hedlund GL, Pacifiico AD, Blair HC Prostaglandin $\mathrm{E}_{1}$-induced hyperostosis: clinicopathological correlations and possible pathogenetic mechanisms. Pediatr Path Lab Med 1996; 16:489-507

10. Cremin BJ, Jamieson DH. Tuberculosis: the resurgence of our most lethal infectious disease - a review. Pediatr Radiol 1995; 25 620-626

11. Cremin BJ, Fisher RM, Levinsohn MW. Multiple bone tuberculosis in the young. $B r$. $J$ of Radiol 1970; 43:638-645

12. Horev G, Korenreich L, Ziv N, Grunebaum M. The enigma of stress fractures in the pediatric age group: clarification or confusion through the new imaging modalities. Pediat Radio 19989; 20:469-471

13. Kozlowski K, Diard F, Padovani J, Sprague P, Pietron K. Unilateral mid-femoral periosteal new bone of varying aetiology in children. Pediatr Radiol 1986; 16:475-482

14. Hoffman EB, de V de Beer SA, Keys G, Anderson P. Diaphyseal primary subacute osteomvelitis in children. J Pediatr Onthop 1990; 10:250-254

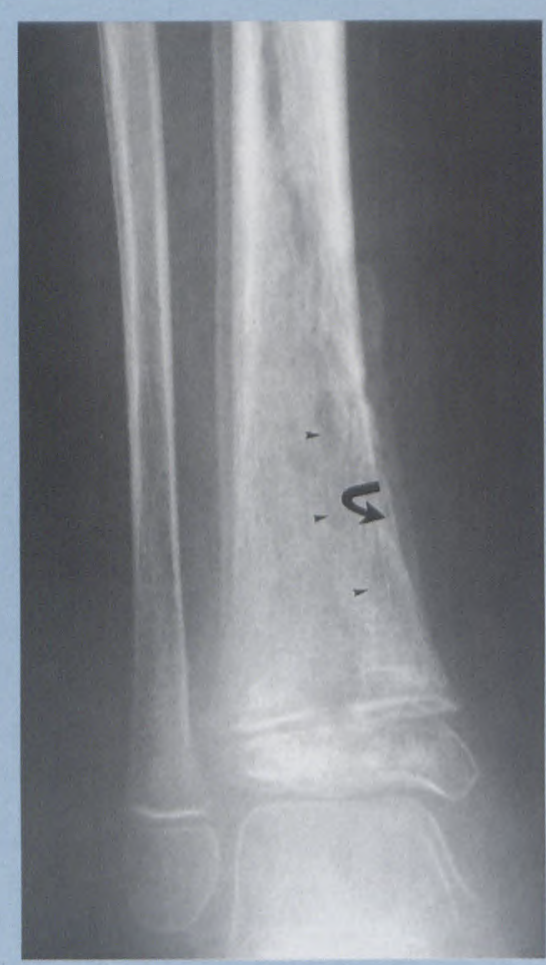

Figure 17: Pyogenic osteomyelitis

III-defined patchy lucencies (arrowheads) of the distal tibial metaphysis and diaphysis with cortical breakthrough (curved arrow) and a periosteal reaction are demonstrated in this case of pyogenic osteomyelitis.

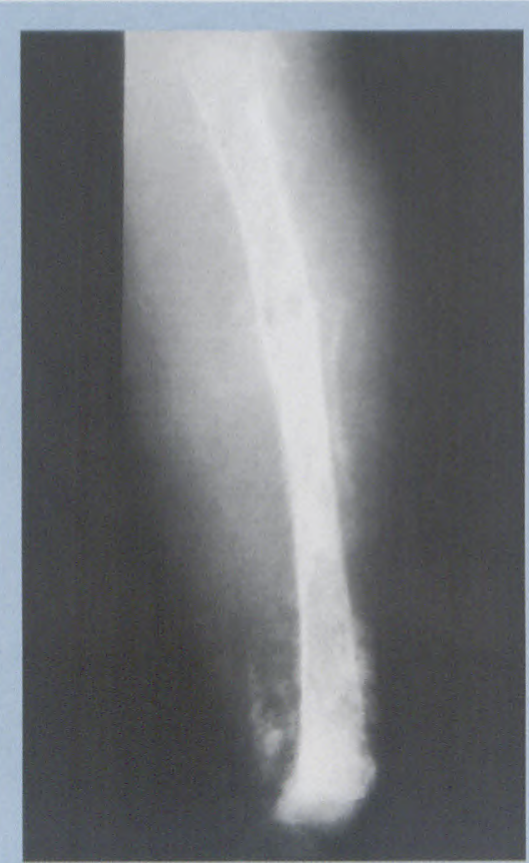

Figure 18: Osteosarcoma

The extensive periosteal reaction is associated with the aggressive malignancy involving the left femur. 